\title{
Alcohol-Induced Ovarian Failure in the Rat
}

\author{
David H. Van Thiel, Judith S. Gavaler, and Roger Lester, Division of \\ Gastroenterology, Department of Medicine, University of Pittsburgh School of \\ Medicine, Pittsburgh, Pennsylvania 15261 \\ RICHARD J. SHERINS, Reproductive Research Branch, National Institutes of \\ Child Health and Human Development, National Institutes of Health, \\ Bethesda, Maryland 20014
}

A B S T R A C T The effect of ethanol feeding on ovarian function and structure in female rats was studied in alcohol-fed animals, isocalorically fed controls, and two ad libitum-fed control groups. Ovarian weight was reduced by $60 \%$ in alcohol-fed animals compared with the control groups. Gross disruption of ovarian architecture was noted, characterized by the absence of any corpus hemorrhagicum and corpus albicans. Moreover, plasma levels of estradiol were significantly reduced in the alcohol-fed animals $(P<0.01)$ compared with the levels found in isocaloric controls. Plasma levels of estrone and corticosterone were increased in alcoholfed and isocaloric control animals relative to those of ad libitum-fed animals suggesting a primarily adrenal, rather than ovarian, origin for these two steroids. Despite the increase in estrone, the secondary sex organs (uterus and fallopian tubes) reflected marked estrogen deprivation presumably as a result of estradiol insufficiency.

Progesterone levels in the alcohol-fed animals were significantly less than levels in the isocaloric and intact ad libitum-fed controls but were not significantly different compared to oophorectomized animals.

Plasma follicle-stimulating hormone levels were similar in alcohol-fed, isocaloric controls, and ad libitum-intact controls. They were, however, one-third the level of oophorectomized controls. Both alcohol-fed and isocaloric controls had increased levels of plasma luteinizing hormone, although levels were below those seen in oophorectomized controls $(P<0.01)$.

The results establish that ingestion of a diet containing 5\% ethanol for periods as short as 6 wk produces functional and histologic ovarian failure in the female rat.

Dr. Van Thiel is the recipient of U. S. Public Health Service Career Development Award AA00016.

Received for publication 25 August 1977 and in revised form 2 November 1977.

\section{INTRODUCTION}

The deleterious effects of alcohol on male sexual function are well documented $(1,2)$. The relation between chronic alcohol abuse and male impotence, sterility, and feminized bodily habitus is widely recognized (35). The mechanisms of alcohol-induced male sexual dysfunction have been explored, and have been shown to be related both to primary testicular failure and to suppression of hypothalamic-pituitary responsiveness $(2,6,7)$.

The development of an animal model of alcohol-induced sexual dysfunction in the male has facilitated research on the pathogenesis of the syndrome (8). The model has permitted study of the effects of alcohol on the hypothalamic-pituitary-gonadal axis under conditions in which the amount of alcohol ingested is known, the effects of superimposed dietary restrictions are controlled, and the contaminating variable of severe associated liver disease is eliminated. The results of studies in the male rat model extend the original studies of Badr and Bartke (9) in mice and have established that alcohol is a testicular toxin, and induces failure of both testicular spermatogenesis and testosteronogenesis (8).

An increasing literature suggests that chronic alcohol abuse may induce failure of female sexual function $(10-22)$. Association of alcoholism with menstrual abnormalities, problems with reproduction, and changes in secondary sex characteristics has been made. The present study was, therefore, undertaken to devise an animal model of alcohol-induced sexual dysfunction in the female and, specifically, to evaluate the effects of alcohol ingestion on ovarian growth, development, and function.

\section{METHODS}

Animals. 100 female white Wistar rats matched for body size and age were obtained from Charles River Breeding 
Laboratories, Wilmington, Mass., and maintained in individual cages. They were divided into four groups: (I) Alcoholfed animals received a liquid diet with ethanol accounting for $36 \%$ of total calories $(8,23)$; (II) pair-fed isocaloric controls were fed a similar diet in which dextrimaltose is isocalorically substituted for ethanol; (III) ad libitum-intact controls and (IV) oophorectomized ad libitum controls were given Wayne Lab Blox F4 diet obtained from Best Feeds, Oakdale, Pa. The experiment ran 49 days from age 28 through age 77 days.

Gross and microscopic anatomy. The animals were sacrificed by exsanguination via the abdominal aorta under light ether anesthesia and autopsied. With this technique, between 6 and $7 \mathrm{ml}$ of blood was obtained from each animal. The liver, ovaries, uterus, and fallopian tubes were removed, trimmed of all extraneous tissue, weighed, and representative sections were placed in Bouin's solution for histological study. Histological sections were prepared and studied with hematoxylin and eosin.

The liver was examined and graded on an arbitrary scale of one to four for degree of fat and for signs of hepatocellular necrosis and inflammation. The ovaries were examined for presence of corpus lutea and corpus hemorrhagica as well as for numbers and development of Graafian follicles. The uterus and fallopian tubes were examined for thickness of the endometrium, type of and secretory activity of the epithelial lining cells, and thickness of the muscle wall of each organ. The cervix and vagina were examined for thickness of epithelial cell lining and signs of estrogen stimulation.

Plasma steroids and gonadotropins. Plasma levels of estradiol and estrone were determined in duplicate using modifications of established radioimmunoassay methods $(24,25)$ so that $100-\mu l$ samples could be assayed. All samples were measured in a single assay, thus eliminating any interassay variation. The detection limit for the estradiol assay was $0.1 \mathrm{pg}$ and for the estrone assay $0.2 \mathrm{pg}$. Intra-assay variation for the estradiol assay was $<5 \%$ and for the estrone assay $<8 \%$.

Plasma levels of progesterone were determined in duplicate using a modification of an established radioimmunoassay (26) so that small plasma samples $(100 \mu \mathrm{l})$ could be measured accurately. All samples were measured in a single assay. The detection limit for the progesterone assay was $10.0 \mathrm{pg}$. Intraassay variation was $<10 \%$.

Plasma levels of corticosterone were measured in duplicate using a radioimmunoassay in the laboratory of Julane Hotchkiss, Ph.D., Department of Physiology, University of Pittsburgh School of Medicine, Pittsburgh, Pa. (27). By this method plasma samples as small as $25 \mu \mathrm{l}$ were easily assayable. The detection limit for the assay was $20 \mathrm{pg}$. Intra-assay variation was $<3 \%$. All of the steroid hormone assays used were validated by running control samples from castrated-adrenalectomized animals with and without added unlabeled steroid as controls.

Radioimmunoassay of plasma gonadotropin levels was performed with reagents supplied by the National Institute of Arthritis and Metabolic Disease (NIAMDD), Rat Pituitary Hormone Distribution Program. NIAMDD-Rat follicle-stimulating hormone RP-1 and NIAMDD-Rat luteinizing hormone RP-1 were used as the reference preparations in the respective assays. Hormones were iodinated with Secretion ${ }^{125}$ I using the chloramine-T method (28). Before their use in the assay, the iodinated hormones were purified with polyacrylamide gel electrophoresis, using $9 \%$ acrylamide with $2 \%$ cross-linking (29). Gels were sliced transversely after hardening at $-70^{\circ} \mathrm{C}$ for $1 \mathrm{~h}$ and the hormones eluted in assay buffer (30). The volume of plasma required for accurate assay by this technique is $100 \mu \mathrm{l} / \mathrm{sample}$. Other details of the assay were as previously described (31). Sensitivity of the assay was 4 $\mathrm{ng} / \mathrm{ml}$ for both follicle-stimulating hormone and luteinizing hormone with an intra-assay variation of $8 \%$. Potency estimates were calculated using the computer program of Rodbard and Lewald (32).

Enzymatic tests of liver function. Serum alkaline phosphatase, gamma glutamyl transpeptidase, glutamic pyruvic, and glutamic oxalacetic transaminase activities were measured utilizing standard micromethods in use by the Clinical Chemistry Laboratories at Presbyterian-University Hospital, Pittsburgh, Pa. A 300- $\mu$ l plasma sample was utilized for each assay. All samples were measured in a single assay thus eliminating any interassay variation.

Blood alcohol. Blood alcohol levels were determined according to the method of Bernt and Gutman (33) using a Beckman DU spectrophometer (Beckman Instruments, Inc., Spinco Div., Palo Alto, Calif.). The blood sample was obtained 1 day before sacrifice between $9 \mathrm{a} . \mathrm{m}$. and $11 \mathrm{a} . \mathrm{m}$., before providing that day's food supply to the animals.

Statistical analysis. The Student's $t$ test was used for all statistical analysis. Differences between groups were considered probably significant at $P<0.05$ and significant at $P<0.01$.

\section{RESULTS}

Growth. Intact and oophorectomized control animals maintained on an ad libitum standard rat diet gained weight steadily throughout the study period and were treated for comparative purposes as a single group (Fig. 1). The alcohol-fed animals and their pair-fed isocaloric controls also gained weight but at a reduced rate. As can be seen in Fig. 1, the alcohol-fed animals and their pair-fed isocaloric controls had identical growth rates through 42 days of age at which point the pair-fed isocaloric controls began to grow more rapidly than the alcohol-fed animals. The pattern of the growth curves for alcohol-fed and pair-fed isocaloric controls, however, were qualitatively similar. At the time of sacrifice, the alcohol-fed animals weighed significantly less $(138.0 \pm 5.3 \mathrm{~g})($ mean $\pm \mathrm{SEM})$ than the isocaloric controls $(161.6 \pm 3.8 ; P<0.01)$. Both the alcohol-fed animals and their pair-fed isocaloric controls weighed less than the ad libitum-fed control animals (184.2 \pm 2.1 ; $P<0.01)$.

Gross and microscopic anatomy. As expected, the livers of the alcohol-fed animals weighed more (10.6 $\pm 0.5 \mathrm{~g}$ ) than those of the pair-fed isocaloric controls $(6.4 \pm 0.3 \mathrm{~g})$ and those of the ad libitum controls (8.3 $\pm 0.2 \mathrm{~g}$; both $P<0.01$ ) (livers obtained from intact and oophorectomized ad libitum animals did not differ). When organ weights were corrected for body weights, differences between alcohol-fed and control groups increased (Table I). The histologic appearance of the liver of the alcohol-fed group was one of marked fatty metamorphosis, whereas that of the ad libitum and pairfed isocaloric controls was normal.

The ovaries of the alcohol-fed animals weighed twofifths as much (30.6 $\pm 2.2 \mathrm{mg}$ ) as those obtained from the pair-fed isocaloric controls $(75.5 \pm 3.9 \mathrm{mg})$ and onethird as much as those of the intact ad libitum controls $(91.4 \pm 0.2 \mathrm{mg}$; both $P<0.01)$ (Fig. 2). When ovarian 


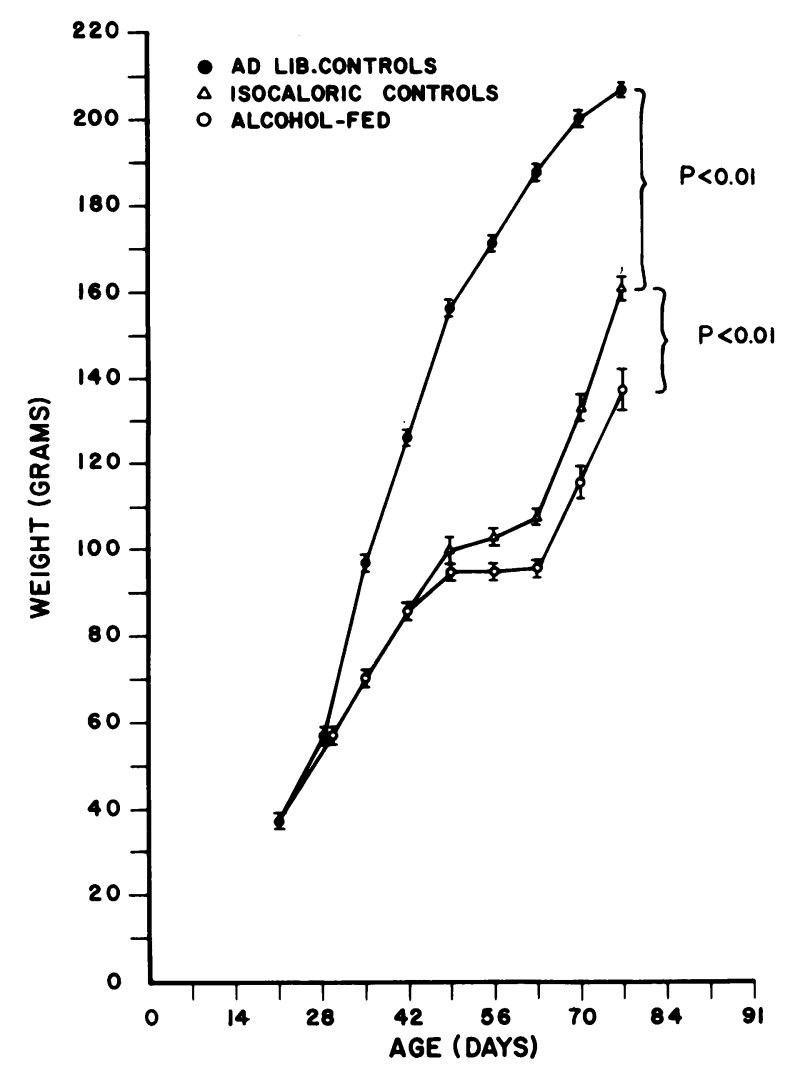

FIGURE 1 Growth curve for the animals studied. The line connecting the open circles represents the curve for the alcohol-fed animals. The line connecting the triangles represents the curve of isocaloric-fed controls. The line connecting the closed circles represents the curve for the intact and oophorectomized controls combined. The brackets at each point represent the mean $\pm S E M$ for each point.

mass was corrected for body mass, alcohol-fed animals still had $<50 \%$ of the ovarian mass present in pair-fed or ad libitum-fed intact controls (Table I). Similarly, the uterus and fallopian tubes of the alcohol-fed animals weighed one-fourth as much $(39.0 \pm 4.1 \mathrm{mg})$ as those of the pair-fed isocaloric controls $(180.5 \pm 18.7 \mathrm{mg})$ and less than one-seventh as much as those of the intact ad libitum controls $(306 \pm 15.5 \mathrm{mg}$; both $P<0.01)$ (Fig. 3 ). When uterine and fallopian tube weight differences were corrected for body weight, the differences between alcohol-fed and the control groups increased, whereas those between the two control groups actually decreased (Table I).

The ovaries obtained from the pair-fed and intact ad libitum controls contained numerous developing and mature follicles, corpus lutea, and corpus hemorrhagica, whereas the stroma represented only a small fraction of the overall ovarian tissue (Fig. 4).

In contrast, the greater part of the ovarian tissue of the alcohol-fed animals consisted of dense stroma. A few immature follicles could be identified, but no large, well-developed follicles were seen. Corpus lutea and corpus hemorrhagica were absent in 41 of the 50 ovaries obtained from alcohol-fed animals. Thus, the reduction in ovarian mass in the alcohol-fed animals was due primarily to an absence of developing follicles, corpus lutea, and corpus hemorrhagica.

The histological appearance of the uterus with its internal lining endometrium and of the fallopian tubes in the ad libitum controls and pair-fed isocaloric controls exhibited a redundant lining composed of columnar epithelial cells rich with secretory granules. In contrast, that of the alcohol-fed animals was one of complete estrogen deprivation, with a single layer of uniform cuboidal cells lacking all signs of secretory activity similar to that of the oophorectomized controls.

The histologic appearance of the cervix and vagina of the pair-fed isocaloric and ad libitum controls showed a relatively thick mature layer of squamous epithelial cells overlying the deeper basal and parabasal cells, whereas that of the alcohol-fed animals was characterized by estrogen deprivation having a thin epithelium of parabasal cells similar to that observed in the oophorectomized animals.

Plasma steroid and gonadotropins. Plasma steroid and gonadotropin concentrations were determined for all the rats in each group from blood obtained at the time of exsanguination.

Plasma estradiol concentrations in the alcohol-fed animals $(27.5 \pm 1.2 \mathrm{pg} / \mathrm{ml})($ mean \pm SEM $; n=25$ for each group) were less than those of the pair-fed controls $(33.3 \pm 1.5 \mathrm{pg} / \mathrm{ml})$ as well as the ad libitum-intact controls $(48.0 \pm 1.4 \mathrm{pg} / \mathrm{ml}$; both $P<0.01)$ but were not sta-

TABLE I

Relative Organ Weights

\begin{tabular}{|c|c|c|c|}
\hline & $\frac{\text { Liver mass }}{\text { Body mass }} \times 10^{-2}$ & $\frac{\text { Ovarian mass }}{\text { Body mass }} \times 10^{-4}$ & $\frac{\text { Uterine mass }}{\text { Body mass }} \times 10^{-4}$ \\
\hline Alcohol-fed rats & $7.6 \pm 0.2 *$ & $2.2 \pm 0.1^{*}$ & $2.8 \pm 0.3^{*}$ \\
\hline Pair-fed isocaloric controls & $3.9 \pm 0.8$ & $4.7 \pm 0.2$ & $11.1 \pm 1.2 \ddagger$ \\
\hline Intact ad libitum controls & $4.5 \pm 0.8$ & $5.0 \pm 0.2$ & $16.7 \pm 0.9$ \\
\hline
\end{tabular}

* $P<0.01$ compared with the pair-fed isocaloric and intact ad libitum controls.

$\ddagger P<0.01$ compared with the alcohol-fed and intact ad libitum controls. 


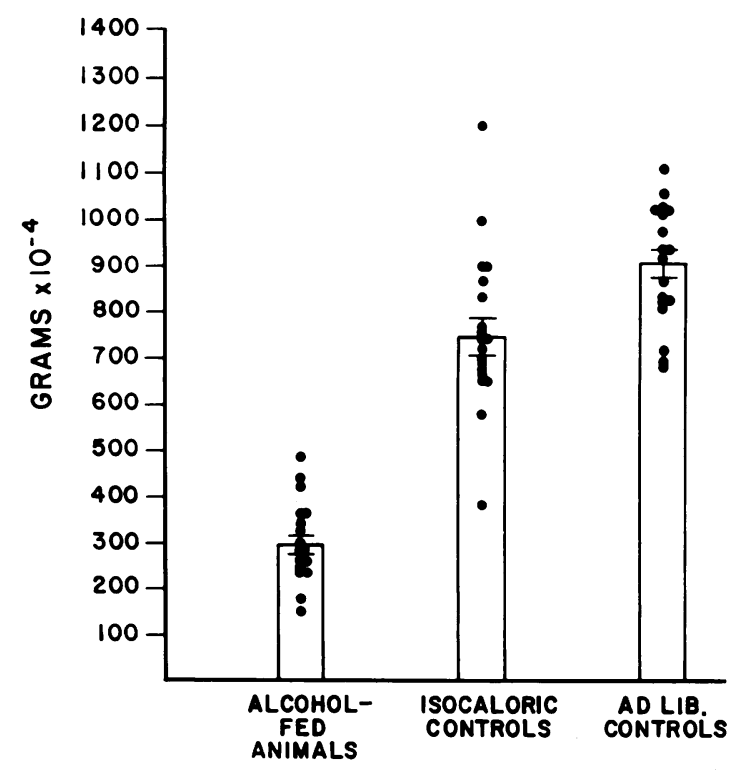

Figure 2 Ovarian weight at time of sacrifice in the animals studied. The ordinate is in terms of grams $\times 10^{-4}$. Along the abcissca are shown the results for each group. The vertical bars represent the mean values for each group, the brackets represent the SEM for each group, and each point represents the results for a given animal studied.

tistically different from those of the oophorectomized ad libitum controls $(29.8 \pm 1.6 \mathrm{pg} / \mathrm{ml})$.

In contrast to this reduction in plasma estradiol levels, plasma estrone concentrations in the alcohol-fed animals $(156.0 \pm 26.7 \mathrm{pg} / \mathrm{ml})$ were greater than those of the pair-fed isocaloric controls $(114.9 \pm 13.9 \mathrm{pg} / \mathrm{ml})$, ad libitum-intact controls $(80.5 \pm 6.3 \mathrm{pg} / \mathrm{ml})$ and oophorectomized controls $(48.0 \pm 5.2 \mathrm{pg} / \mathrm{ml}$; all $P<0.01)$.

Plasma progesterone levels in the alcohol-fed animals $(23.3 \pm 4.3 \mathrm{ng} / \mathrm{ml})$ were significantly less than those of the isocaloric $(54.3 \pm 7.3 \mathrm{ng} / \mathrm{ml})$ and ad libitum-fed controls $(41.7 \pm 6.7 \mathrm{ng} / \mathrm{ml}$; both $P<0.01)$ and, further, were not statistically different from those of the oophorectomized control animals $(18.0 \pm 0.6 \mathrm{ng} / \mathrm{ml})$.

Plasma corticosterone levels in the alcohol-fed animals $(74.0 \pm 9.0 \mu \mathrm{g} / \mathrm{dl})$ and their pair-fed isocaloric controls $(78.0 \pm 9.0 \mu \mathrm{g} / \mathrm{dl})$ were increased relative to the two ad libitum control groups $(48.0 \pm 6.0 \mu \mathrm{g} / \mathrm{dl}$; both $P<0.05)$.

Plasma follicle-stimulating hormone levels in alcohol-fed animals ( $159.0 \pm 12.8 \mathrm{ng} / \mathrm{ml}$ ), isocaloric controls $(181.0 \pm 16.2 \mathrm{ng} / \mathrm{ml})$, and intact ad libitum-fed animals $(167.3 \pm 23.3 \mathrm{ng} / \mathrm{ml})$ were not statistically different. All were significantly less $(P<0.01)$ than those of the oophorectomized ad libitum-fed controls $(690.0$ $\pm 75.2 \mathrm{ng} / \mathrm{ml}$ ).

Plasma luteinizing hormone levels in the alcohol-fed animals $(68.7 \pm 5.7 \mathrm{ng} / \mathrm{ml})$ and isocaloric controls $(79.4$ $\pm 6.8 \mathrm{ng} / \mathrm{ml})$ were increased $(P<0.01)$ relative to those of the ad libitum-fed controls $(43.5 \pm 7.0 \mathrm{ng} / \mathrm{ml})$. All groups had plasma luteinizing hormone levels significantly less than those of the oophorectomized ad libitum-fed animals $(107.0 \pm 18.3 \mathrm{ng} / \mathrm{ml}$; all $P<0.01)$.

Biochemical liver function. Both serum glutamic oxalo-acetic-acid-transaminase and serum glutamic pyruvic transaminase levels were two to two and a half times higher in the alcohol-fed animals compared with those of any control group (all $P<0.01$; Table II). Alkaline phosphatase activity was $50 \%$ greater in the alcohol-fed animals than in any of the control groups (all $P<0.01$ ). Gamma glutamyl transpeptidase activity was not detected in any of the control groups but was reproducibly measurable in the alcohol-fed animals.

Blood alcohol. Blood alcohol levels in the alcoholfed animals were $110 \pm 9.0 \mathrm{mg} / \mathrm{dl}$. Alcohol was undetectable in the serum of any of the control animals.

\section{DISCUSSION}

A considerable body of evidence has accrued during the past $10-15 \mathrm{yr}$ which establishes that alcohol is a metabolic poison not only for the traditional target

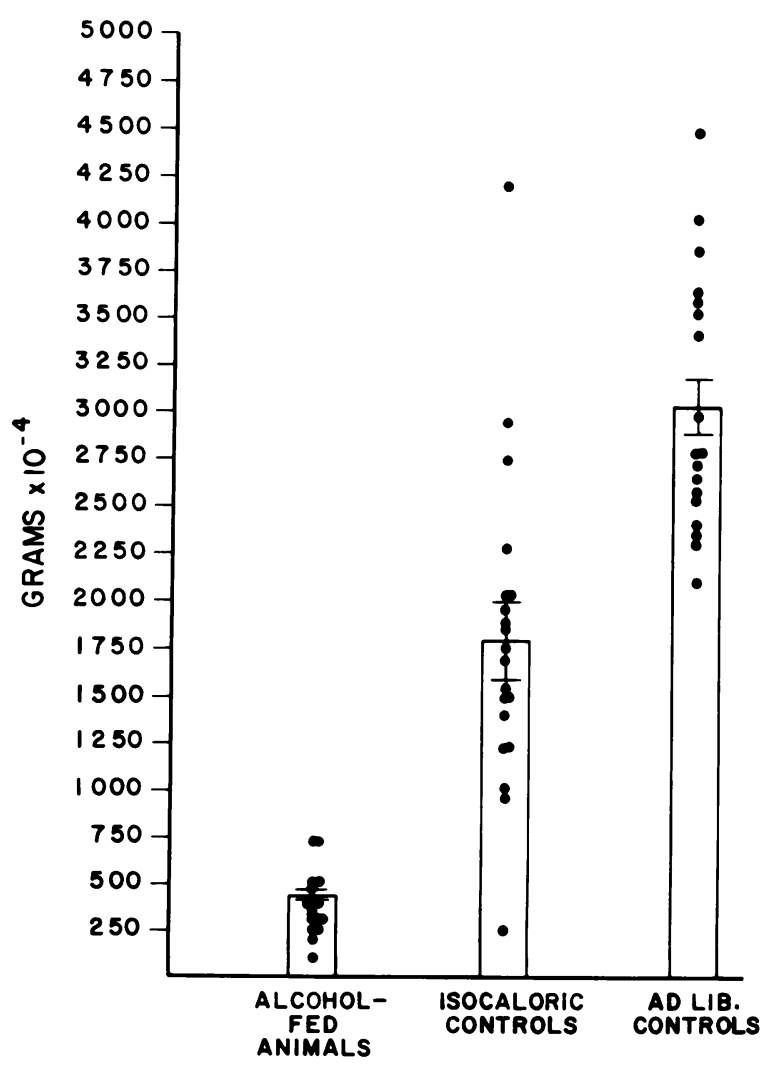

FIGURE 3 Weight of the uterus and fallopian tubes of the animals studied. The ordinate is in terms of grams $\times 10^{-4}$. Along the abcissca are shown the results for each group. See legend for Fig. 2 for other details. 


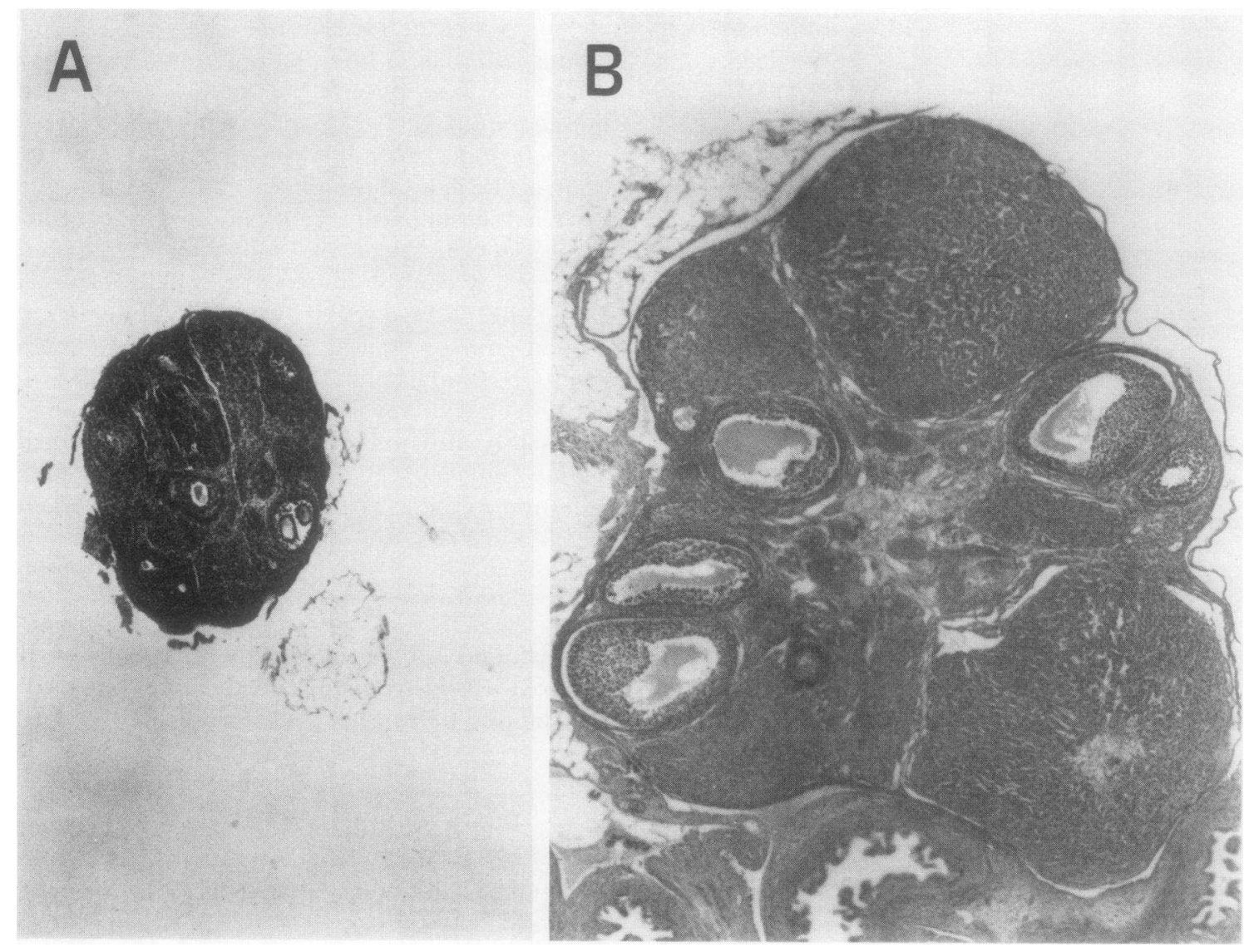

Figure 4 Composite gross anatomic and histologic appearance of the rat ovaries studied. (A) Photomicrograph of a section through the center of an ovary obtained from an isocaloric control. $\times 40$. (B) Photomicrograph of a section through the center of an ovary obtained from an alcohol-fed rat. Sections stained using hematoxylin and eosin. Note the paucity of follicles and absence of corpus hemorrhagica and corpus lutea in the atrophic ovary obtained from the alcohol-fed animal but their presence in the ovary obtained from the isocaloric control animal.

organs, the liver and pancreas, but also for the heart, brain, kidney, and other tissues (34-39). The hypothalamic-pituitary-gonadal axis of the male has been shown to be such a target of alcohol toxicity $(6,7)$ although the effects of coexistent liver disease, avitaminosis, and malnutrition may also have contributed to the observed hypothalamic-pituitary dysfunction observed. Similarly, testicular atrophy, gynecomastia, changes in body hair distribution, and vascular changes are well known accompaniments of chronic alcoholism (3-5). Increased plasma levels and production rates for androstenedione have been reported in alcoholic men with cirrhosis (39-41). Therefore, the hyperestrogenization and hypoandrogenization of male alcoholics are, in part, derivative effects of alcohol-induced liver disease. Thus, the presence of decreased hepatocellular function and portal-systemic shunting of blood permits increased availability of androstenedione at sites peripheral to the liver for conversion to estrone (39-
44). Similarly, accelerated hepatic metabolism of testosterone and increased hepatic conversion of testosterone to estradiol are thought to occur in men with alcoholic liver disease although overall testosterone clearance is retarded in men with cirrhosis (41).

It is equally true, however, that a part of the syndrome of feminization of male alcoholics is attributable to direct effects of alcohol on endocrine tissue. Certain of the signs of hyperestrogenization and hypoandrogenization can be seen in alcoholic men with minimal structural or functional evidence of liver dysfunction (6). Overt decreases in plasma testosterone concentrations are demonstrable in normal volunteers if alcohol ingestion is maintained for periods of several days (2, 7). Interruption of spermatogenesis, diminished testosterone synthesis and androgenicity, and testicular atrophy can be produced in alcohol-fed male rats with minimal evidence of liver disease (8).

The prominence of the signs and symptoms of femi- 
nization has served to focus investigative attention on the causes of sexual endocrinopathy in male alcoholics. Although systematic endocrinologic studies have yet to be performed, evidence is now beginning to accumulate that alcohol may adversely affect sexual function in females as well (10-15). Clinical studies suggest that abortion and premature delivery may be induced by liver disease of any etiology, possibly through effects mediated by excess accumulation of bile acids (45). It has been suggested that the metabolicendocrinologic functioning of the fetal-placental unit may be deranged (46) and that fetal growth and development may be diminished by excessive ingestion of alcohol during pregnancy $(47-53)$. The absence of recognizable corpora hemorrhagica and(or) corpora lutea in the ovaries of premenopausal age female alcoholics has been reported (10).

Accordingly, to see whether elements of what appears to be a syndrome of alcohol-induced sexual dysfunction in females could be reproduced in an animal model, and to dissect out effects due to alcohol per se, rather than to alcohol-induced liver disease, hypothalamic-pituitary-gonadal function was studied in female rats fed alcohol.

The results demonstrate that alcohol is a gonadal toxin in female rats, and produces marked disruption of ovarian structure and function. Ingestion of 5\% ethanol diet for $7 \mathrm{wk}$ resulted in a marked reduction in ovarian weight. Instead of the numerous developing follicles of various sizes and corpus lutea present in the isocaloric control-fed animals, the ovaries of the alcohol-fed animals lacked corpus lutea, had only small atretic follicles, and consisted primarily of dense ovarian stroma (Fig. 4). A corresponding decrease in plasma estradiol concentrations was observed, and levels in alcohol-fed female rats were indistinguishable from those of the oophorectomized control group. As would be anticipated with structural and functional ovarian failure, estrogen target organs were of decreased size and showed histologic evidence of estrogen deficiency.

It is improbable that these effects were secondary to alcohol-induced liver disease. Although the livers of alcohol-fed animals were enlarged, histologic examination showed only fatty metamorphosis, and biochemical tests of hepatic function were only minimally deranged (Table II). Similarly, ovarian failure could not be ascribed exclusively or even predominantly to caloric deprivation. Whereas the isocaloric control group showed significant decreases in ovarian weight, estrogen target organ weight, and plasma estradiol concentrations when compared with rats fed ad libitum, the group ingesting alcohol had significantly lower measures for each of these parameters, and the marked disruption of ovarian architecture present in the alcohol group was not observed in the isocaloric control group. It appears reasonable to conclude, therefore, that the deficits of ovarian structure and function observed in the alcohol-fed rats were in considerable measure the result of toxic effects of ethanol or its metabolic derivatives per se.

It is of interest that despite the significant reduction in estradiol levels in the alcohol-fed animals, plasma estrone levels were increased. Human male alcoholics with markedly reduced testosterone levels have increased plasma levels of estrone $(43,54,55)$, and some authors report increased plasma levels of estradiol as well $(56,57)$. This estrone is derived primarily by peripheral conversion of androstenedione which arises from the adrenal gland (40-44). Although specific studies have not been performed to confirm this point in our model, we propose that the increased levels of estrone in our alcohol-fed and pair-fed isocaloric control female rats are derived similarly from androstenedione of adrenal origin. Such an assumption is consistent with the fact that in both the alcohol-fed and pair-fed isocaloric control animals, estrone and corticosterone are increased presumably due to an increased adrenal secretion occurring as a consequence of the stress of prolonged alcohol feeding and relative starvation associated with pair feeding. Other possibilities exist, however. Perhaps such increases are of ovarian origin. It may also be that alcohol interferes with

TABLE II

Biochemical Liver Function

\begin{tabular}{lcccc}
\hline & SGOT* & SGPT & $\begin{array}{c}\text { Alkaline } \\
\text { phosphatase }\end{array}$ & $\begin{array}{c}\text { Transpeptidase } \\
\text { gamma glutamyl }\end{array}$ \\
\hline & $I U / m l$ & $I U / m l$ & $I U / m l$ & $I U / m l$ \\
Alcohol-fed rats & $65 \pm 14 \S$ & $52 \pm 20^{*}$ & $956 \pm 204^{*}$ & $2.3 \pm 0.6^{*}$ \\
Pair-fed isocaloric controls & $23 \pm 8$ & $21 \pm 10$ & $601 \pm 26$ & Undetectable \\
Intact ad libitum controls & $25 \pm 8$ & $20 \pm 9$ & $603 \pm 34$ & Undetectable \\
Oophorectomized ad libitum controls & $24 \pm 7$ & $16 \pm 9$ & $596 \pm 28$ & Undetectable \\
\hline
\end{tabular}

* Serum glutamic oxalo-acetic acid-transaminase.

\$ Serum glutamic pyrivic transaminase.

$\S P<0.01$ compared with all control groups. 
estrone clearance in rats, or increases conversion of estradiol to estrone. An ovarian origin seems unlikely because of the marked ovarian atrophy present. The present studies provide no data concerning the proposition whether or not ethanol reduces the clearance of estrone in rats. Finally, an increased conversion of estradiol to estrone seems most unlikely as a result of the known redox changes induced in alcohol-fed animals. Regardless of its site of origin, the observed increase of plasma estrone in the alcohol-fed animals is not enough to maintain the normal appearance of the ovary and the other estrogen-responsive tissues in these animals (Figs. 2-4 and Table I). Because the increases in estrone are quite significant, the possibility also exists that alcohol ingestion has somehow produced a defect in uptake of estrogen to target tissue or some effect at a distant point in hormone action.

The mechanism of alcohol-induced ovarian failure remains in question. The ovary contains alcohol dehydrogenase (58), and ovarian metabolism of alcohol with the local accumulation of toxic metabolites comparable to phenomena believed to occur in the testes is thus possible. Several hypotheses for specific mechanisms of direct alcohol-induced ovarian toxicity might be proposed. Ovarian conversion of ethanol to acetaldehyde, with resultant mitochondrial dysfunction, might occur. Several steps in estrogenogenesis, including the conversion of pregnenolone to progesterone by 3 beta-hydroxy steroid dehydrogenase and delta 5-4 isomerase, are NAD dependent (59). The depletion of ovarian stores of NAD by conversion to NADH as the result of ovarian ethanol metabolism might diminish estradiol synthesis. The absence of alcohol dehydrogenase activity in the adrenal gland might explain the resistance of this organ to alcohol-induced injury and the excessive accumulation of plasma estrone derived from adrenal steroidogenesis as described above.

Alternatively, or more likely, in addition, ovarian failure in alcohol-fed female rats may be the result not only of direct effects of alcohol on the ovary, but also of depression of hypothalamic-pituitary function. Chronic alcoholic men have normal to moderately elevated plasma gonadotropin concentrations, often in the face of markedly decreased plasma testosterone concentrations $(1,6,42,56,57,60)$. This has been interpreted to suggest the presence of diminished hypothalamic-pituitary function in such men, and this suggestion has been confirmed by studies establishing that chronic alcoholic men have reduced plasma gonadotropin responses to clomiphene and luteinizing hormone releasing factor $(6,7)$. Moreover, normal volunteers fed moderate quantities of alcohol for periods of $<1 \mathrm{wk}$ have reduced luteinizing hormone responses to luteinizing hormone releasing factor (7). It can, therefore, by hypothesized that alcohol produces gonadal failure in males by decreasing hypothalamic- pituitary stimulation of the gonad through the direct toxic effects of alcohol and(or), secondarily, through peripheral effects of alcohol ingestion.

In the present study, plasma follicle stimulating hormone concentrations were not significantly different for the alcohol-fed, isocaloric, and ad libitum groups despite the marked lowering of plasma estradiol concentrations in the former. Plasma luteinizing hormone concentrations were raised for the alcohol-fed and isocaloric groups as compared with the ad libitum group, but not to the levels obtained in the oophorectomized group. The results are not unequivocal and may have been produced by the limited caloric intake of alcoholfed animals. Nevertheless, the limited gonadotropin response to the ovarian ablation present in the alcoholfed group raises the possibility that alcohol ingestion alters hypothalamic-pituitary function in females. Validation of this view will require assessment of the gonadotropin responses to hypothalamic and pituitary stimulation in alcohol-fed subjects.

\section{ACKNOWLEDGMENTS}

The authors are indebted to Doctors E. Knobil and J. Hotchkiss of the Department of Physiology, University of Pittsburgh School of Medicine, for their help with the corticosterone assay.

This work was supported in part by the National Institutes of Health grant AA()145().

\section{REFERENCES}

1. Van Thiel, D. H., and R. Lester. 1976. Alcoholism: its effect on hypothalamic-pituitary-gonadal function. Gastroenterology. 71: 318-327.

2. Gordon, G. G., K. Altman, A. L. Southren, E. Rubin, and C. S. Lieber. 1976. Effect of alcohol (ethanol) administration on sex-hormone metabolism in normal men. N. Engl. J. Med. 295: 793-797.

3. Sherlock, S. 1975. Diseases of the Liver and Biliary System. Blackwell Scientific Publications Ltd., Oxford. 5th edition. 64-83.

4. Conn, H. O. 1975. Cirrhosis. In Diseases of the Liver. L. Schiff, editor. J. B. Lippincott Co., Philadelphia. 4th edition. 833-939.

5. Lieber, C. S., L. Feinman, and E. Rubin. 1976. Alcohol and the liver. In Gastroenterology. H. L. Bockus, editor. W. B. Saunders Company, Philadelphia. 3rd edition. 342365.

6. Van Thiel, D. H., R. Lester, and R. J. Sherins. 1974. Hypogonadism in alcoholic liver disease: evidence for a double defect. Gastroenterology. 67: 1188-1199.

7. Van Thiel, D. H., J. S. Gavaler, J. Vaitukaitis, and R. Lester. 1976. Evidence for an isolated defect in pituitary secretion of LH in chronic alcoholic men. Gastroenterology. 71: A40/933. (Abstr.)

8. Van Thiel, D. H., J. S. Gavaler, R. Lester, and M. D. Goodman. 1975. Alcohol-induced testicular atrophy: an experimental model for hypogonadism occurring in chronic alcoholic men. Gastroenterology. 69: 326-332.

9. Badr, R. M., and A. Bartke. 1974. Effect of ethyl alcohol on plasma testosterone levels in mice. Steroids. 23: 921-928.

10. Jung, Y., and A. B. Russfield. 1972. Prolactin cells in the 
hypophysis of cirrhotic patients. Arch. Pathol. 94: 265-269.

11. Paisseau, G., and V. Ounanasky. 1930. Syndrome hypophysaire avec cirrhose du doie et splénomégalie. Bull. Mém. Soc. Med. Paris. 54: 267-273.

12. Laignel-Lavastine, J. Troiser, and Y. Boquien. 1931. Association de la cirrhose de foie a une depilation plus ou moins complete et a une insufficance thyroovarenne. Bull. Mém. Soc. Med. Paris. 47: 829-837.

13. Rollerston, H. 1933. Diseases of the Liver. Oxford Medical Press, Oxford. 3: 303-333.

14. Hartwell, S. W., and W. J. Johnson. 1937. Unusual relation between menstrual function and ascites in a case of juvenile cirrhosis of the liver. J.A.M.A. (J. Am. Med. Assoc.) 109: $1800-1801$.

15. Ratnoff, O. D., and A. J. Patek, Jr. 1942. The natural history of Laennec's cirrhosis of the liver: analysis of 386 cases. Medicine (Baltimore). 21: 207-268.

16. Hardy, H. L., and R. Feemster. 1946. Infectious hepatitis in Massachusetts. N. Engl.J. Med. 235: 147-157.

17. Lloyd, C. W. R., and R. H. Williams. 1948. Endocrine changes associated with Laennec's cirrhosis of the liver. Am. J. Med. 4: 315-330.

18. Pincus, I. J., A. E. Rakoff, E. M. Coh, and H. J. Tumen. 1951. Hormonal studies in patients with chronic liver disease. Gastroenterology. 19: 735-754.

19. Cameron, C. B. 1957. Urinary excretion of oestrone, oestradiol-17 $\beta$ and oestriol in patients with liver disease. J. Endocrinol. 15: 199-205.

20. Aschkenasy-Lelu, P. 1958. Action des boissons alcoolises sur le rendement reproducteur du rat. C. R. Acad. Sci. Agric. Bulg. 246: 1275-1277.

21. Cranston, E. M. 1958. Effect of tranquilizers and other agents on sexual cycle of mice. Proc. Soc. Exp. Biol. Med. 98: $320-322$.

22. Aron, E., M. Flanzy, C. Combescot, J. Puisais, J. Demaret, F. Reynouard-Brault, and C. Igert. 1965. L'alcool estildans le vin l'element qui perturbe, chez la ratte, le cycle vaginal? Bull. Acad. Natl. Med. (Paris). 149: 112-120.

23. Lieber, C. S., and L. M. DeCarli. 1970. Quantitative relationship between amount of dietary fat and severity of alcoholic fatty liver. Am. J. Clin. Nutr. 23: 474-478.

24. Hotchkiss, J., L. E. Atkinson, and E. Knobil. 1971. Time course of serum estrogen and luteinizing hormone (LH) concentrations during the menstrual cycle of the Rhesus monkey. Endocrinology. 89: 177-183.

25. Loriaux, D. L., H. J. Ruder, and M. B. Lipsett. 1972. The measurement of estrone sulfate plasma. Steroids. 18: 463-472.

26. Abraham, G. E., R. Swerdloff, D. Tulchinsky, and W. D. Odell. 1971. Radioimmunoassay of plasma progesterone. J. Clin. Endocrinol. Metab. 32: 619-624.

27. Spätt, A., and J. Sára. 1972. Competitive protein binding assay of corticosterone. J. Steroid Biochem. 3: 755-759.

28. Greenwood, F. C., W. M. Hunter, and J. S. Glover. 1963. The preparation of ${ }^{131}$ I-labeled human growth hormone of high specific radioactivity. Biochem. J. 89: 114-123.

29. Rodbard, R., and A. Chramback. 1971. Estimation of molecular radius free mobility, and valence using polyacylamide gel electrophoresis. Ann. Biochem. Exp. Med. (Calcutta). 40: 95-134.

30. Sherins, R. J., J. Vaitukaitis, and A. Chrambach. 1973. Physical characterization of hFSH and its desialyation products by isoelectric focusing and electrophoresis in polyacrylamide gel. Endocrinology. 92: 1135-1141.

31. Odell, W. D., and R. S. Swerdloff. 1968. Radioimmunoassay of luteinizing and follicle-stimulating hormones in human serum. In Radio-Isotopes in Medicine. Proceed- ings of a symposium held at Oak Ridge Associated Universities, Tennessee. R. L. Hayes, F. A. Goswitz, and Beverley E. Pearson Murphy, editors. (CONF-671111) Oak Ridge, Tenn. 165-184.

32. Rodbard, D., and J. E. Lewald. 1970. Computer analysis of radioligand assay and radioimmunoassay data. Proceedings of the 2nd Symposium Steroid Assay by Protein Binding, Karolinska Institutet, Stockholm. 79-103.

33. Bernt, E., and I. Gutman. 1974. Ethanol determination with alcohol dehydrogenase and NAD. In Methods of Enzymatic Analysis. H. U. Bergmeyer, editor. Academic Press, Inc., New York. 3: 1499-1502.

34. Lieber, C. S., N. Spritz, and L. M. DeCarli. 1966. Accumulation of triglycerides in heart and kidney after alcohol ingestion. J. Clin. Invest. 45: 1041A. (Abstr.)

35. Van Thiel, D. H., J. S. Gavaler, J. M. Little, and R. Lester. 1977. Alcohol: its effect on the kidney. Metab. Clin. Exp. 26: $857-866$.

36. Corrodi, H., K. Fuxe, and T. Hokfelt. 1966. The effect of ethanol on the activity of central catecholamine reserve in rat brain. J. Pharm. Pharmacol. 18: 821-823.

37. Moss, J. N., R. D. Smyth, H. Beck, and G. J. Martin. 1967. Ethanol impact on brain acetylcholine and its modification by cysteine. Arch. Int. Pharmacodyn. Ther. 108: 235-238.

38. Badr, R. M., and R. S. Badr. 1975. Induction of dominant lethal mutation in male mice by ethyl alcohol. Nature (Lond.). 253: 134-136.

39. Van Thiel, D. H., W. D. Williams, Jr., J. S. Gavaler, J. M. Little, L. W. Estes, and B. S. Rabin. 1977. Ethanol: its nephrotoxic effect in the rat. Am. J. Pathol. 89: 67-84.

40. Edman, C. D., P. C. MacDonald, and B. Combes. 1975. Extraglandular production of estrogens in subjects with liver disease. Gastroenterology. 69: 819A. (Abstr.)

41. Gordon, G. G., J. Olivo, F. Rafii, and A. L. Southren. 1975. Conversion of androgens to estrogens in cirrhosis of the liver. J. Clin. Endocrinol Metab. 40: 1018-1026.

42. Kley, H. K., E. Nieschlag, W. Wiegelmann, H. G. Solbach, and H. L. Krüskemper. 1975. Steroid hormone and their binding in plasma of male patients with fatty liver, chronic hepatitis, and liver cirrhosis. Acta. Endocrinol (Kbh). 79: $275-285$.

43. Olivo, J., G. G. Gordon, F. Rafii, and A. L. Southren. 1975. Estrogen metabolism in hyperthyroidism and in cirrhosis of the liver. Steroids. 26: 47-56.

44. Crowell, G. C., S. E. Rin, and J. R. K. Preedy. 1963. Program of the Endocrine Society 45th Annual Meeting, June 1963. Abstract 88.

45. Borhammanesh, F., and P. Haghighi. 1970. Pregnancy in patients with cirrhosis of the liver. Obstet. Gynecol. 36: 315-324.

46. Smith, D. W., K. L. Jones, and J. W. Hanson. 1976. Perspectives on the cause and frequency of the fetal alcohol syndrome. Ann. N.Y. Acad. Sci. 273: 138-139.

47. Green, H. G. 1974. Infants of alcoholic mothers. Am. J. Obstet. Gynecol. 118: 713-716.

48. Mulvihill, J. J., J. T. Klimas, D. C. Stokes, and H. M. Risemberg. 1976. Fetal alcohol syndrome: seven new cases. Am. J. Obstet. Gynecol. 125: 937-941.

49. Randall, C. L., W. J. Taylor, and D. W. Walker. 1977. Ethanol-induced malformation in mice. Alcohol. Clin. Exp. Res. 1: 219-224.

50. Sander, L. W., P. A. Snyder, H. L. Rosett, A. Lee, J. B. Gould, and E. Quellette. 1977. Effects of alcohol intake during pregnancy on newborn state regulation. Alcohol. Clin. Exp. Res. 1: 233-241.

51. Martin, J., D. C. Martin, C. A. Lund, and A. P. Streissguth. 1977. Maternal alcohol ingestion and cigarette smoking 
and their effects on new born conditioning. Alcohol. Clin. Exp. Res. 1: 243-247.

52. Russell, M. 1977. Intrauterine growth in infants born to women with alcohol-related psychiatric diagnoses. Alcohol. Clin. Exp. Res. 1: 225-231.

53. Jones, K. L., D. W. Smith, C. N. Ulleland, and A. Pytkowicz Streissguth. 1973. Pattern of malformation in offspring of chronic alcoholic mothers. Lancet. I: 1267-1271.

54. Van Thiel, D. H., J. S. Gavaler, R. Lester, D. L. Loriaux, and G. D. Braunstein. 1975. Plasma estrone, prolactin, neurophysin, and sex steroid binding globulin in chronic alcoholic men. Metab. Clin. Exp. 24: 1015-1019.

55. Pentikäinen, P. J., L. A. Pentikäinen, D. L. Azarnoff, and C. A. Dujovne. 1975. Plasma levels and excretion of estrogens in urine in chronic liver disease. Gastroenterology. 69: $20-27$.

56. Chopra, I. J., D. Tulchinsky, and F. L. Greenway. 1973.
Estrogen-androgen imbalance in hepatic cirrhosis. Ann. Intern. Med. 79: 198-203.

57. Baker, H. W., H. G. Burger, D. M. de Kretser, A. Dulmanis, B. Hudson, S. O'Connor, C. A. Pulsen, N. Purcell, G. C. Rennie, C. S. Seah, H. P. Tast, and C. Wang. 1976. A study of the endocrine manifestations of hepatic cirrhosis. Q.J. Med. 45: 145-178.

58. Deane, H. W., B. L. Lobel, and S. L. Romney. 1962. Enzymatic histochemistry of normal human ovaries of the menstrual cycle, pregnancy, and the early puerperium. Am. J. Obstet. Gynecol. 83: 281-294.

59. Richardson, G. S. 1975. Hormonal physiology of the ovary. In Gynecologic Endocrinology. J. J. Bold, editor. Harper \& Row, Publishers, Inc., New York. 2nd edition. 55-77.

60. Galväo-Teles, A., C. W. Burke, D. C. Anderson, and J. C. Marshall. 1973. Biologically active androgens and oestradiol in men with chronic liver disease. Lancet. I: 173-177. 